\title{
A Study of CT Versus MR Arthrography in Detection of Acetabular Cartilage Defects and Labral Tears
}

\author{
Eman Gaber Mohamed Al-Saadawy, Ashraf Mohammed Enite, Ahmed Mahmoud Sayed* \\ Radiodiagnosis Department, Faculty of Medicine, Al-Azhar University for Girls, Cairo, Egypt \\ *Corresponding author: Ahmed Mahmoud Sayed, Mobile: (+20) 01113751521, E-Mail: amboeyad@ gmail.com
}

\begin{abstract}
Background: the most important role of imaging in the preoperative period is to reveal labro-cartilaginous lesions in patients with chronic hip pain and suggested FAI. MRI particularly 3T MRI has a good ability to detect labral and chondral pathologies in FAI.

Objective: to evaluate CT hip arthrography in the detection of acetabularlabral lesions and articular cartilage defects in comparison with MR arthrography in patients with chronic intractable hip pain.

Patients and Methods: this is a cross sectional study in Cairo Scan Radiology center and Al-Azhar University hospital over 5 years period. The study included 61 patients who were referred for identification of source of chronic hip pain or assessing previous hip arthroscopic intervention. All cases were subjected to evaluation by both MDCT and MR arthrography. Confirmation of diagnosis was primarily based upon MR arthrography findings.

Result: sixty-one patients were included in this study. Of them, 51 patients have been proved to have intra articular pathology; 31 males (61\%) and 20 females (39\%). Femoro-acetabular deformities were readily detectable via CT arthrography. Compared to MRA, CT arthrography had a sensitivity and specificity of $90.7 \%$ and $100 \%$ in detection of acetbularlabral lesions, $95 \%$ and $100 \%$ specificity in detection of femoral and acetabularchondral lesions, and $86 \%$ and $100 \%$ specificity in the detection of other intra articular pathologies, respectively.

Conclusion: multidetector CT arthrography is an efficient alternative to MR arthrography in the evaluation of internal derangements of the hip.
\end{abstract}

Keywords: Labral tear, Cartilage loss, Para-labral cysts and ossification, CTA and MRA

\section{INTRODUCTION}

Acetabular labral tears are a recently recognized cause of hip pain in the absence of plain radiographic abnormalities. Typical presenting signs and symptoms in patients with labral tears include persistent pain, clicking, locking, and decreased range of motion ${ }^{(1)}$.

Improvements in surgical techniques have meant that chondral lesions and labral tears are amenable to surgical intervention. As orthopedic surgeons become more comfortable performing arthroscopic surgery on the hip joint, labral abnormalities are more frequently being addressed by means of minimally invasive surgery. Accurate preoperative identification of labral tears by the radiologist has therefore become an area of increasing interest ${ }^{(2)}$. As with other joints in the body, magnetic resonance (MR) arthrography of the hip has emerged as a technique of choice for diagnosis of internal derangement of the hip ${ }^{(3)}$.

Both non-contrast MRI and MR arthrography have limitations in terms of spatial resolution, which can make the detection of subtle labral and cartilage pathology challenging ${ }^{(4)}$.

3D-CT play an important role in the evaluation of osseous anatomy and paralabral ossifications in femoroacetabular impingement ${ }^{(5)}$.

MDCT arthrography, with its exquisite spatial resolution and high intra-articular contrast resolution, is a viable alternative (widely available, rapid, robust, and well tolerated) to MRI and MR arthrography in the evaluation of internal derangements of the hip ${ }^{(6)}$.

\section{AIM OF THE WORK}

To evaluate CT hip arthrography in the detection of acetabularlabral lesions and articular cartilage defects in comparison with MR arthrography in patients with chronic intractable hip pain.

\section{PATIENTS AND METHODS}

We conducted a randomized cross sectional study in Cairo Scan Radiology center and Sayed Galal University hospital over 5 year-period. The study included 61 patients who were referred for identification of the source of chronic hip pain or assessing previous hip arthroscopy.

The study was approved by the Ethics Board of Al-Azhar University and an informed written consent was taken from each participant in the study.

All cases were subjected to both $\mathrm{CT}$ and MR Arthrography (CTA and MRA), confirmation of diagnosis was primarily based upon MRA findings.

\section{Inclusion criteria}

- Those patients who had previous intervention or those who have metallic prosthesis degrading MRI images.

- Failed or inconclusive MRI studies.

- Preoperative planning of osseous and cartilage abnormalities. 


\section{Exclusion criteria}

- Patients known to have contraindications for MRI e.g. implanted magnetic device like pacemakers.

- Native MRI detectable cause of hip pain e.g. femoral neck stress fracture, AVN or migratory osteoporosis.

\section{Statistical analysis}

Data will be analyzed using Statistical Package for Social Sciences (SPSS) software program, version 20 (SPSS Inc., Chicago, Illinois, USA). Qualitative variable were recorded as frequencies and percentages and were compared by chi-square test. Quantitative measures were presented as means \pm standard deviation (SD) and were compared by student $\mathrm{t}$ - test. $\mathrm{P}$ value $<0.05$ was considered significant.

\section{RESULTS}

Sixty one patients were included in this study. Out of them, 51 patients proved to have intra articular pathology.

Hip articular derangement 51 patients' ages were ranging from 16 to 57 years with a mean age and SD of 31.63 \pm 11.18 years. The included 51 patients with intra articular pathology have been found to be of higher male incidence; 31 males $(61 \%)$ and 20 females (39\%). However there was no significant association between sex and incidence of IA pathology with $\mathrm{P}$ value of 0.0963 .

All patients with intra articular pathology were categorized according to MRA finding into 3 groups:

- $\quad$ Group I (37 patients): those with chondro-labral pathology

- Group II (8 patients): those patients with IA pathology other than chondro-labral pathology.

- Group III (6 patients): those with mixed pathologies.

\section{Intra articular pathology count}

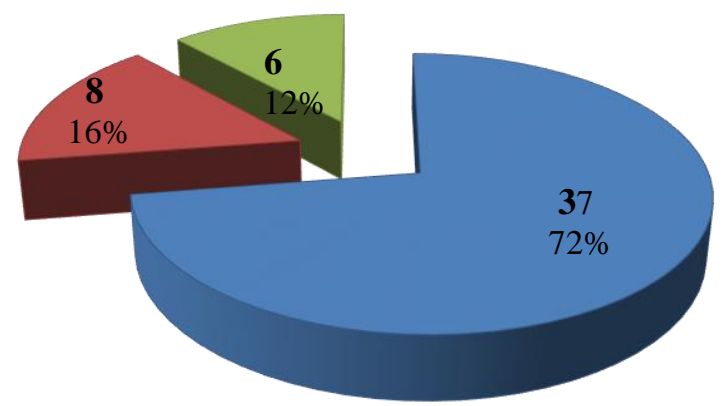

$\square$ Labral-chondral $\square$ Other IA pathology $\square$ Mixed

\section{Group I patients:}

Patients in group I included those patients with labral-chondral pathology, it included 37 patients with age range from 16 to 57 years old. The mean age and STDV are $31.56 \pm 10.66$ years.

Their results were expressed statistically regarding Labral and Chondral categories separately via CTA in comparison to MRA.

CTA was totally capable of detection of complete labral-chondral separation (12/12) and labral ossification (3/3) but missed 4 cases of partial labralchondral separation (18/22).

Table (1): Illustration of statistical figures for the assessment of labral lesions via CTA versus MRA

\begin{tabular}{|c|c|c|c|c|}
\hline & Sensitivity & Specificity & $\begin{array}{c}\text { Positive } \\
\text { Predictive } \\
\text { value }\end{array}$ & $\begin{array}{c}\text { Negative } \\
\text { Predictive } \\
\text { value }\end{array}$ \\
\hline CTA/ & 89 & $100 /$ & $100 /$ & $67 /$ \\
MRA & $/ 100 \%$ & $100 \%$ & $100 \%$ & $100 \%$ \\
\hline
\end{tabular}

Regarding detection of chondral lesions; CTA was able to detect most of chondral lesions compared to MRA (21/22).

Table (2): Illustration of statistical figures for the assessment chondral lesions via CTA versus MRA

\begin{tabular}{|l|c|c|c|c|}
\hline & Sensitivity & Specificity & $\begin{array}{l}\text { Positive } \\
\text { Predictive } \\
\text { value }\end{array}$ & $\begin{array}{c}\text { Negative } \\
\text { Predictive } \\
\text { value }\end{array}$ \\
\hline $\begin{array}{l}\text { CTA/ } \\
\text { MRA }\end{array}$ & $95 / 100 \%$ & $100 /$ & $100 /$ & $94 /$ \\
& & $100 \%$ & $100 \%$ & $100 \%$ \\
\hline
\end{tabular}

\section{Group II patients:}

Patients included non chondro-labral IA pathology, it included 8 patients with age range from 17 to 37 years old. The mean age and STDV are 27.25 \pm 6.98 years.

Other IA pathologies were classified as follows;

Table (3): Illustration of non chondro-labral intra articular pathology distribution

MRA detected types of non chondro-labral intra

$$
\text { articular pathology }
$$

\begin{tabular}{|l|l|}
\hline Adhesive / synovial bands & $\mathbf{4}$ \\
\hline Synovial masses & $\mathbf{1}$ \\
\hline $\begin{array}{l}\text { Femoral Herniation pits / } \\
\text { fibrocystic changes }\end{array}$ & $\mathbf{1}$ \\
\hline Ligamentum teres injury & $\mathbf{1}$ \\
\hline Femoral Osteochondral lesion & $\mathbf{1}$ \\
\hline
\end{tabular}

CTA compared to MRA had the following statistics in the detection of non chondro-labral intra articular pathologies; 
Table (4): Illustration of statistical figures of non chondro-labral pathologies via CTA versus MRA

\begin{tabular}{|c|c|c|c|c|}
\hline $\begin{array}{l}\text { Type } \\
\text { CTA/ } \\
\text { MRA }\end{array}$ & Sensitivity & Specificity & $\begin{array}{l}\text { Positive } \\
\text { Predictive } \\
\quad \text { value }\end{array}$ & $\begin{array}{l}\text { Negative } \\
\text { Predictive } \\
\text { value }\end{array}$ \\
\hline $\begin{array}{c}\text { OC } \\
\text { lesions }\end{array}$ & $\begin{array}{c}100 / \\
100 \%\end{array}$ & $\begin{array}{c}100 / \\
100 \%\end{array}$ & $\begin{array}{c}100 / \\
100 \%\end{array}$ & $\begin{array}{c}100 / \\
100 \%\end{array}$ \\
\hline $\begin{array}{c}\text { Adhesive } \\
\text { bands }\end{array}$ & $\begin{array}{c}75 / \\
100 \%\end{array}$ & $\begin{array}{c}100 / 100 \\
\%\end{array}$ & $\begin{array}{c}100 / \\
100 \%\end{array}$ & $\begin{array}{c}80 / \\
100 \%\end{array}$ \\
\hline $\begin{array}{c}\text { Synovial } \\
\text { masses }\end{array}$ & $\begin{array}{c}100 / \\
100 \%\end{array}$ & $\begin{array}{c}100 / \\
100 \%\end{array}$ & $\begin{array}{c}100 / \\
100 \%\end{array}$ & $\begin{array}{c}100 / \\
100 \%\end{array}$ \\
\hline HPs & $\begin{array}{c}100 / \\
100 \%\end{array}$ & $\begin{array}{c}100 / \\
100 \%\end{array}$ & $\begin{array}{c}100 / \\
100 \%\end{array}$ & $\begin{array}{c}100 / \\
100 \%\end{array}$ \\
\hline $\begin{array}{c}\text { LT } \\
\text { injury }\end{array}$ & $\begin{array}{c}100 / \\
100 \%\end{array}$ & $\begin{array}{c}100 / \\
100 \%\end{array}$ & $\begin{array}{c}100 / \\
100 \%\end{array}$ & $\begin{array}{c}100 / \\
100 \%\end{array}$ \\
\hline
\end{tabular}

\section{Group III patients:}

Patients included those patients with mixed labralchondral and non chondro-labral IA pathology, it included 6 patients with age range from 16 to 57 years old. The mean age and STDV are $37.83 \pm 16.69$ years.

CTAcompared to MRA had the following statistics the detection of non chondro-labral intra articular pathologies.

Table (5): Illustration of statistical figures of non chondro-labral pathology via CTA versus MRA

\begin{tabular}{c|c|c|c|c|}
$\begin{array}{c}\text { Type } \\
\text { CTA/MRA }\end{array}$ & Sensitivity Specificity & $\begin{array}{c}\text { Positive } \\
\text { Predictive } \\
\text { value }\end{array}$ & $\begin{array}{c}\text { Negative } \\
\text { Predictive } \\
\text { value }\end{array}$ \\
\hline OC lesions & $100 /$ & $100 /$ & $100 /$ & $100 /$ \\
& $100 \%$ & $100 \%$ & $100 \%$ & $100 \%$ \\
HPs & $100 /$ & $100 /$ & $100 /$ & $100 /$ \\
& $100 \%$ & $100 \%$ & $100 \%$ & $100 \%$ \\
\hline LT injury & $67 /$ & $100 /$ & $100 /$ & $75 /$ \\
& $100 \%$ & $100 \%$ & $100 \%$ & $100 \%$ \\
\hline
\end{tabular}

Table (6): Illustration of statistical figures of labral pathology via CTA versus MRA

\begin{tabular}{|c|c|c|c|c|}
\hline & Sensitivit & Specificity & $\begin{array}{l}\text { Positive } \\
\text { Predictive } \\
\text { value }\end{array}$ & $\begin{array}{l}\text { Negative } \\
\text { Predictive } \\
\text { value }\end{array}$ \\
\hline $\begin{array}{l}\text { CTA/ } \\
\text { MRA }\end{array}$ & $\begin{array}{c}95 / \\
100 \%\end{array}$ & $\begin{array}{c}100 / \\
100 \%\end{array}$ & $\begin{array}{c}100 / \\
100 \%\end{array}$ & $\begin{array}{c}96 / \\
100 \%\end{array}$ \\
\hline
\end{tabular}

\section{Femoro-acetabular deformities and associated IA} pathology:

There is evident positive association between femoro-acetbular deformities and incidence of intra articular pathology. FA deformities were found in 37 (72\%) patients with intra articular pathology.Chi squared tests denoted significant $P$ value of 0.025 .

The most common FA deformity types associated with intra articular pathologies were acetbular dysplasia and mixed (Cam and Pincer) types representing $100 \%$ and $85 \%$ of their number respectively.
Table (7): Frequency Distribution of the specific types of FA deformities according to IA pathology

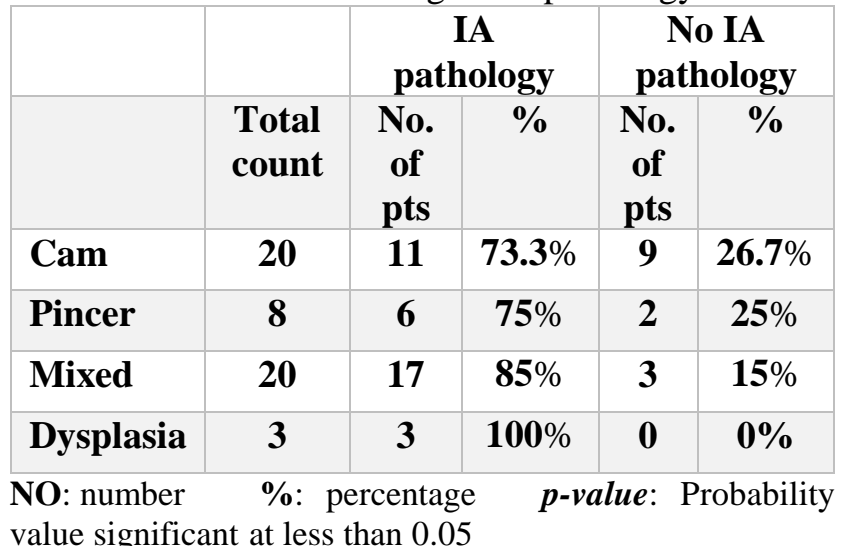

FA deformities were most frequently associated with labral-chondral (group I) and Mixed (group III) types of IA pathology representing $78 \%$ and $83 \%$ respectively of each specific group.

FA deformities were readily detectable via CTAwith excellent correlation relative to MRA (100\% sensitivity and specificity).

\section{Paralabral cysts and ossifications:}

Some of patients have shown para labral ossification or cysts. CTA has shown excellent correlation to MRA in the detection of para labral ossifications but much less accuracy for the detection of para labral cysts.

Table (8): Illustration of statistical figures of paralabral ossifications and cysts via CTA versus MRA

\begin{tabular}{|l|c|c|c|c|}
\hline $\begin{array}{l}\text { CTA/ } \\
\text { MRA }\end{array}$ & Sensitivity Specificity & $\begin{array}{l}\text { Positive } \\
\text { Predictive } \\
\text { value }\end{array}$ & $\begin{array}{c}\text { Negative } \\
\text { Predictive } \\
\text { value }\end{array}$ \\
\hline $\begin{array}{l}\text { Para } \\
\text { labral } \\
\text { ossifications }\end{array}$ & $100 /$ & $100 /$ & $100 /$ & $100 /$ \\
\hline $\begin{array}{l}\text { Para } \\
\text { labral cysts }\end{array}$ & $100 \%$ & $100 \%$ & $100 \%$ & $100 \%$ \\
\hline
\end{tabular}

\section{DISCUSSION}

The most important role of imaging in the preoperative period is to reveal labro-cartilaginous lesions in patients with chronic hip pain and suggested $\mathrm{FAI}^{(7)}$.

During the past 2 decades there have been numerous studies that focused on the use of MRI, including both non-contrast and direct arthrographic methods, to identify intra-articular hip pathologies. MRI particularly 3T MRI has a good ability to detect labral and chondral pathologies in $\mathrm{FAI}^{(8)}$.

In the literature there is a relatively small number of studies investigating the use of CTA in the evaluation of intra-articular hip pathologies. The success rate of surgery mostly depends on knowing the exact location of labral tears.

CTA has the advantage of demonstrating the exact location of a tear by means of its multiplanar imaging 
capabilities. MDCT arthrography has a very high sensitivity compared to that of MRA for the demonstration of articular cartilage loss in the hip ${ }^{(4)}$.

However, when considering the new hippreserving surgical techniques, assessing biochemical properties of cartilage before structural breakdown becomes of more importance. MRI Cartilage mapping techniques such as delayed gadolinium-enhanced MR imaging of cartilage (dGEMRIC), T2 mapping and T1r mapping seem to be well-suited for early detection of preclinical cartilage damage ${ }^{(9)}$.

Niishi et al. $^{(10)}$ have investigated the ability of MDCT arthrography to assess disorders of the acetabulum and labrum in hip dysplasia using radial reformatted images. They compared imaging findings with those of arthroscopy in approximately $50 \%$ of patients.

Christie-Large $\boldsymbol{e t} \boldsymbol{a l}^{(\mathbf{1 1})}$ have investigated in a retrospective study the role of MDCT arthrography in the evaluation of suspected intra-articular hip pathologies and compared imaging findings with those of arthroscopy and open surgery in approximately $30 \%$ of patients

Perdikakis et $\boldsymbol{a l}^{\left({ }^{(12)}\right.}$ study done in 2011 have investigated in a retrospective study the diagnostic ability of MRA and CTA in depicting surgically proven hip labral tears and articular cartilage degradation using arthroscopic and open surgery findings as the standard of reference

Sahin et al. ${ }^{(13)}$ study done most recently in $\mathbf{2 0 1 4}$ has investigated patients with FAI via combined CTA and MRA of the hip in a prospective study compared to arthroscopy.

In the current study, we aimed at evaluation of CTA of the hip in the detection of acetbular labral tear, chondral injuries as well as other intra articular pathologies relative to MRA (unfortunately we had a lack of arthroscopic correlation).
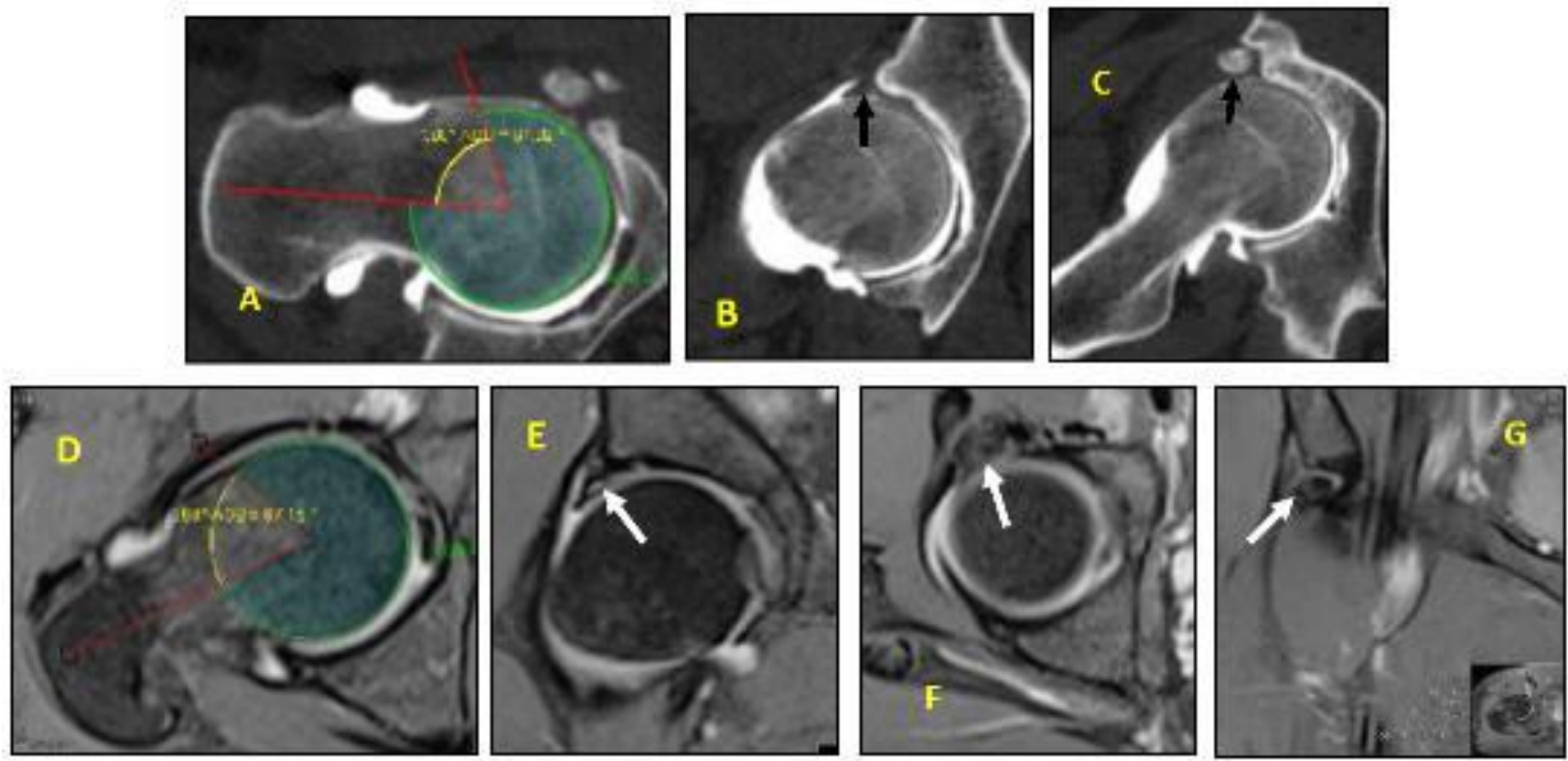

Figure (1): A 37 years old male complaining from anterior hip pain related to motion with relieved pain after intra articular (IA) anaesthetic injection; (A, B and C) Reformatted CT imagesshowing antero-superior Cam deformity of the femoral neck, oblique linear contrast insinuation undermining the antero-superior acetbular labrum, large anterosuperior para labral ossification [arrows]. (D) Axial PD FS WI showing Antero-superior femoral Cam deformity. (E) Corornal PD FS WI showing Partial chondro-labral separation of the antero-superior labrum, (F and G) Axial and Coronal PD FS WIs showing subtle Paralabral ossifications adjacent to anterior inferior iliac spine [arrows]. 

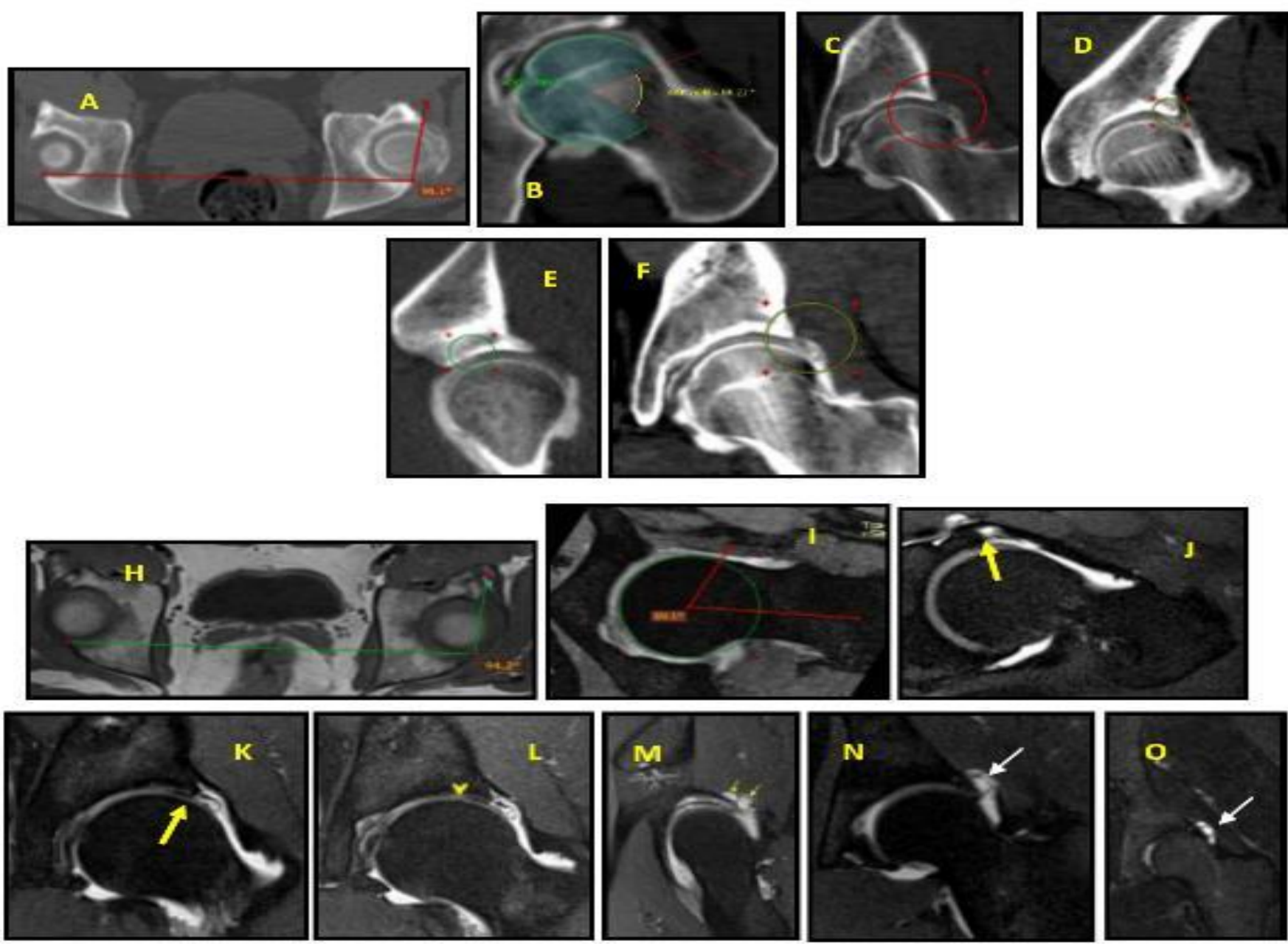

Figure (2): A 29 old Male patient presented with severe anterior groin pain during rest and exaggerated with movement with limited abduction, partially resolved symptoms after IA local anaesthesia. (A) Axial CT image showing Focal cranial acetabular retroversion. (B) Reformated Radial CT image showing femoral neck focal anterosuperior Cam deformity. (C, Dand E) Coronal and Sagittal reformatted CT images showing superior acetbular labrum complex tear with adjacent Full thickness cartilage loss at labral-chondral transitional zone. (F) Subtle faintly opacified superior Para labral cyst [ellipses]. (H) Axial T1 WIs showing focal acetabular cranial retroversion with estimated angle of $-4^{\circ}$. (I) Reformatted T1 VIBE FS WIs of the femoral neck showing antero-superior femoral Cam deformity with maximum estimated $\alpha$-angle of $69^{\circ}$. (J, K and L) Axial oblique and Coronal PD FS WIs showing superior labrum Complete labral-chondral separation with detached flap tear [arrows] with adjacent superior acetabular focal full thickness chondral loss [arrowhead]. (M, N and O) Sagittal and Coronal PD FS and STIR WIs showing multi-locular para labral cyst [arrows] related to acetabular labral tear.
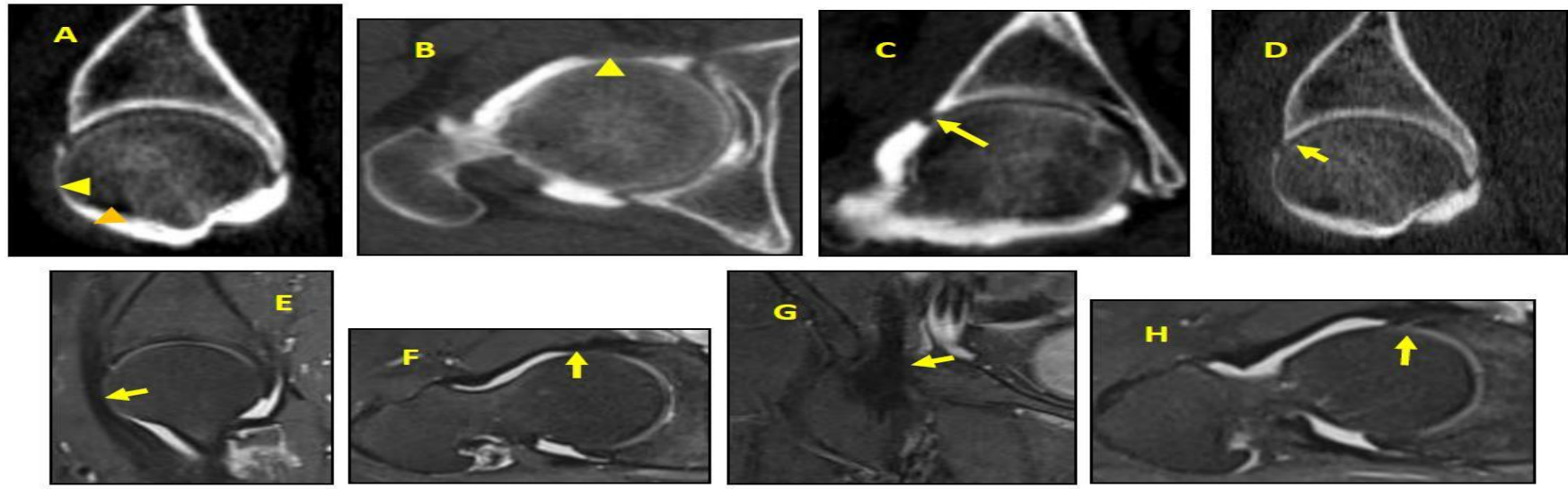

Figure (3): A 23 years old male presernted with right anterior dynamic hip pain, incompletely resolved pain after IA local anaesthetic injection (A) Sagittal reformatted and (B) Axial CT image showing Thickened broadened ilio-psoas tendon abutting the anterior capsulolabral complex [arrowheads]. (C and D) Reformatted Coronal and Sagittal CT image showing acetabular labrum focal antero-superior complete labral-chondral separation [arrows]. (E, F and G) Sagittal, oblique Axial and Coronal PD FS WIs showing Thickened broadened ilio-psoas tendon abutting the anterior capsulolabral complex [arrows]. (H) Oblique Axial PD FS WIs showing Focal antero-superior labral tear underneath the ilio-psoas tendon [arrow] (?Iliopsoas impingement) 

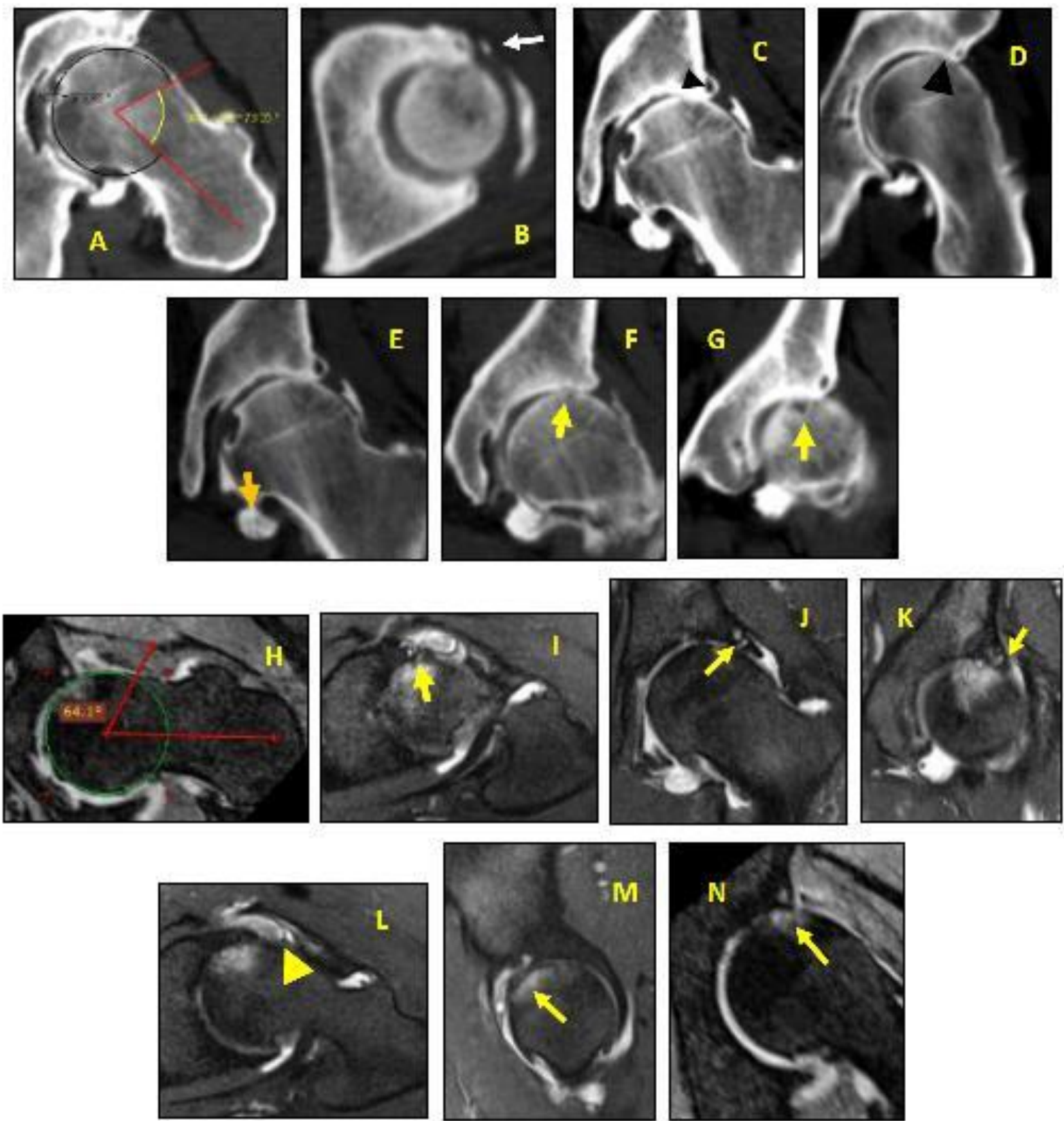

Figure (4): A 30 years old male complaining from Severe dynamic hip pain recently has become persistent, Partially relieved after IA local anaesthetic injection. (A)Reformatted Radial CT image showing femoral neck antero-superior Cam deformity. (B) Axial CT images showing anterior-superior para labral ossification [arrow]. (C) Reformatted Coronal CT image showing paralabral intra osseous cyst [arrowhead] and fovea capitis marginal osteophytes. No definite labral-chondral separation. (D) Reformatted Radial CT images of the acetabular labrum showing complete chondral loss of the opposing antero-superior femoro-acetabular articular surfaces with bone-to-bone contact [arrowhead]. (E, F And G)Reformatted Coronal CT images showing intra synovial bizzare shaped rice bodies and ahesions, chondral loss with subchondral erosions and pseudocystic changes [arrows].(H) Reformatted Radial T1 VIBE FS WI of the femoral neck showing femoral neck antero-superior Cam deformity. (I) Oblique Axial and (J and K) Coronal PD FS WIs showing antero-superior partial labral-chondral separation [arrow] with related paralabral cyst containing synovial adhesions [arrowhead]. (L and M)oblique Axial and Sagittal PD FS and (N) reformatted Radial T1 VIBE FS WIs of Advanced secondary osteoarthritic changes with Femoro-acetabular antero-superior subchondral pseudocysts. (advanced osteoarthritis) 

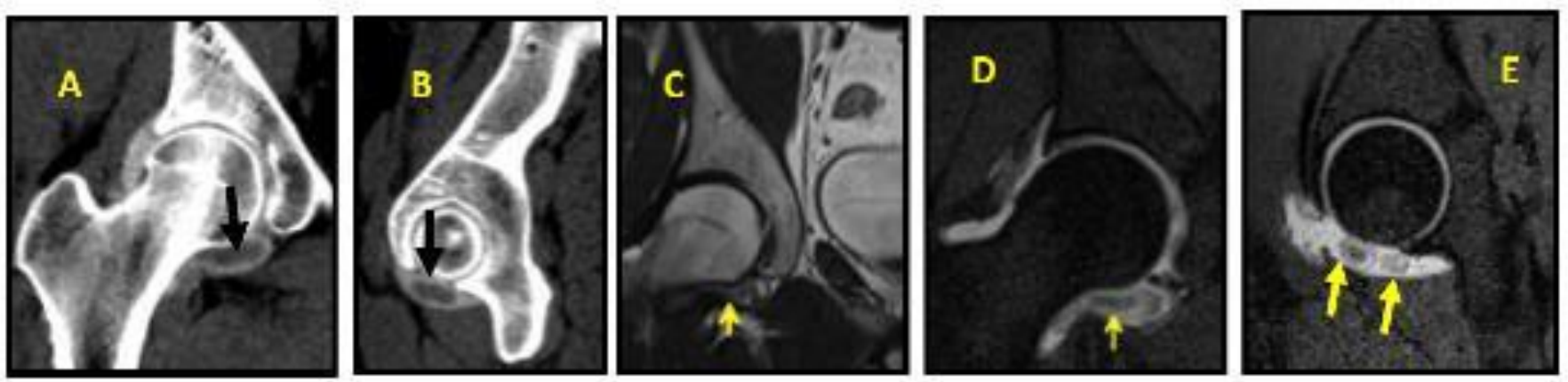

Figure (5): A 28 years old male complaining from hip pain and limited range of motion, relieved pain after IA anaesthetic injection. (A and B) Reformatted Coronal and Sagittal CT images showing ovoid shaped shaped floating synovial soft tissue masses within the inferior synovial recess [arrows].(C) Coronal T2 WIs showing globular shaped low signal synovial mass within the inferior synovial recess [arrows]. (D and E) Coronal and Sagittal PD FS WIs showing Intra synovial discrete nodular soft tissue lesions of low PD signal [arrows]. (focal pigmented villo-nodular synovitis)
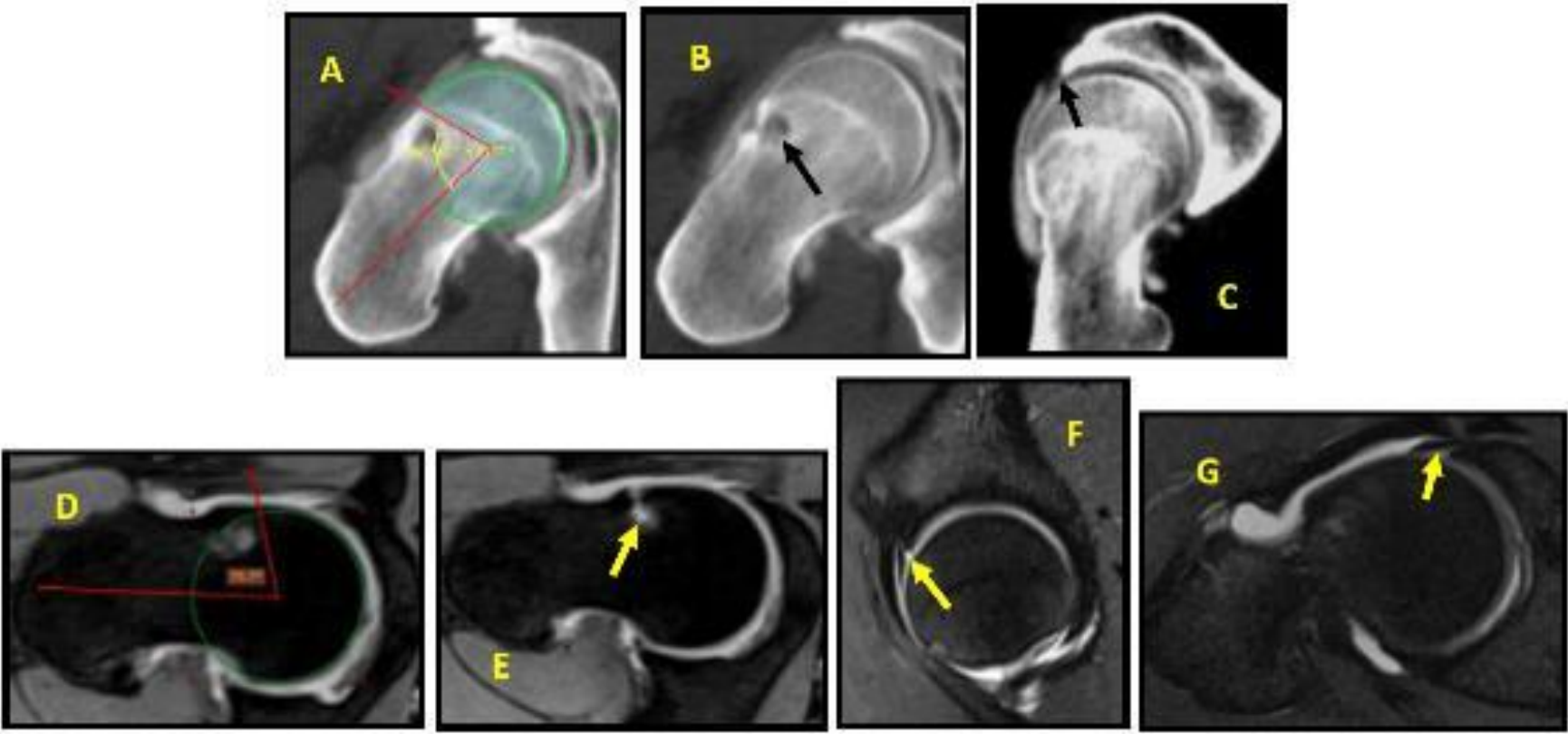

Figure (6): A 16 years old athelete male Marathone runner complaining from anterior dynamic hip pain for 2 months duration, Mildly ameliorated hip poin after IA anaesthetic injection.(A)Reformatted Radial CT image showing anterosuperior femoral neck Cam deformity. (B) Reformatted Radial CT image showing antero-superior femoral neck contrast-opacified fibrocystic disease [arrow]. (C) Reformatted Radial CT image showing antero-superior labrum contrast insinuation undermining its base [arrow].(D) Reformatted Radial T1 VIBE FS WI showing femoral neck antero-superior Cam deformity opposite 2 O'clock position. (E) Reformatted Radial T1 VIBE FS WI showing contrastfilled herniation pit of the femoral neck antero-superior aspect [arrow]. (F and G) Sagittal and oblique Axial PD FS WIs showing antreo-superior partial labral-chondral separation[arrows]. 


\section{Acetabular labral lesions:}

In the current study; we used Mahorn Classification in the characterization of labral lesion and clock-face pattern for the localization of labral lesions. The current study concluded overall excellent capability of CTA in detection of acetabularlabral lesions compared to MRA and showed $90.7 \%$ sensitivity and $100 \%$ specificity.

This matched with Christie-Large et al.$^{(11)}$ and Sahin et al. ${ }^{(13)}$ studies who concluded excellent correlation of CTA and Sahin $\boldsymbol{e l} \boldsymbol{~ a l .}{ }^{(13)}$ reported that CTA seems to have an equal sensitivity and a higher specificity than MRA for the detection of labral pathology with the percent sensitivity and specificity for correctly assessing the labral tearing were as follows for MRA / CTA respectively: 100/100 and $50 / 100(\mathrm{P}<0.05)$.

\section{Femoro-acetabular catilage loss:}

In the current study; we identified cartilage injury by either detectable via CTA or not. MRA was much better in the assessment of degree of chondral injury and early chondral derangement however CTA found to have excellent capability in the detection of femoral and acetabular chondral loss lesions with 95\% sensitivity and $100 \%$ specificity.

This matched with Christie-Large et $\boldsymbol{a l} .{ }^{(11)}$ study who reported excellent correlation of CTA for the detection of acetabular and femoral cartilage loss with sensitivity and specificity found to be $90 \%$ and $88 \%$ respectively, Perdikakis et al. ${ }^{(12)}$ concluded that CTA showed better, but not statistically significantdemonstration of the articular cartilage loss whereas Sahin et $\boldsymbol{a l} .^{(\mathbf{1 3})}$ study concluded that MRA is better, but not statistically significantly, in demonstrating acetabular and femoral cartilage pathology.

\section{LIMITATIONS OF THE STUDY}

Limited number of cases of the study as well as single radiology center experience arenot reliable to make the study of high credibility.

Absent arthroscopic correlations for most of cases due to lack of institutional, co-ordinated and multidepartmental cooperation. Feedback from arthroscopic orthopedicians and post-interventional follow up imaging may impart more strength and credibility to such a study.

Radiation exposure for young adolescent patients was an issue of concern because of gonadal exposure for both sexes.

\section{CONCLUSION}

This study supported arguments for the popular use of MRA as the imaging method of choice in determining intrarticular hip pathologies. But CTA seems to have a close sensitivity and similarspecificity to MRA in detecting labral pathologies.

This study also showed that MRA is much better in the assessment of degree of chondral injury but CTA proved almost similar sensitivity and specificity for detection of femoro-acetabularchondral loss and delamination injuries.

CTA might be used as an efficient alternative in patients for whom MRI is contraindicated, claustrophic or having intra articular metallic fixation prosthesis.

Multi-center radiology experience and coordinated radiological -arthroscopic feedback will add much more accuracy and credibility to this study.

\section{REFERENCES}

1. Bedi A, Kelly BT(2013):Femoroacetabular impingement. J Bone Joint Surg Am., 95(1):82-92.

2. Carstensen SE,McCrum EC,Pierce JL et al. (2017): Magnetic Resonance Imaging (MRI) and Hip Arthroscopy Correlations. Sports Med Arthrosc Rev., 25(4):199-209.

3. Tian CY, Wang JQ, Zheng ZZ et al. (2014): $3.0 \mathrm{~T}$ conventional hip MR and hip MR arthrography for the acetabularlabral tears confirmed by arthroscopy. Eur J Radiol., 83(10):1822-7.

4. Wyler $A$,Bousson $V$ and Bergot $C$ (2009): Comparison of MR arthrography and CT arthrography in hyaline cartilagethickness measurement in radiographically normal cadaver hips with anatomy as gold standard. Osteoarthritis Cartilage, 17(1):19-25.

5. Samim M, Eftekhary N, Youm T et al. (2018): 3D-MRI versus 3D-CT in the evaluation of osseous anatomy in femoroacetabular impingement. Annu Meet SocSkeletRadiol., 48(3):429-436.

6. Tobalem F, Dugert E, Verdun FR et al. (2014): MDCT Arthrography of the Hip: Value of the Adaptive Statistical Iterative Reconstruction technique and potential for radiation dose reduction. Am J Roentgenol., 203(6):W66573

7. Griffin JW, Weber AE, Kuhns B et al. (2016): Imaging in Hip Arthroscopy for Femoroacetabular Impingement: A Comprehensive Approach. Clin Sports Med., 35(3):331344

8. Chopra A, Grainger AJ, Dube B et al. (2018): Comparative reliability and diagnostic performance of conventional $3 \mathrm{~T}$ magnetic resonance imaging and $1.5 \mathrm{~T}$ magnetic resonance arthrography for the evaluation of internal derangement of the hip. EurRadiol., 28(3):963-971

9. Guglielmi G, Biccari N, Mangano F et al. (2010): 3T magnetic resonance imaging of the musculoskeletal system. Radiol Med., 115(4):571-84

10. Nishii T, Tanaka H, Sugano $\mathbf{N}$ et al. (2007): Disorders of the acetabular labrum and articular cartilage in hip dysplasia: evaluation using isotropic high-resolutional CT arthrography with sequential radial reformation. Osteoarthritis Cartilage, 15(3):251-7

11. Christie-Large M, Tapp MJF, Theivendran $\mathrm{K}$ et al. (2010): The role of multidetector CT arthrography in the investigation of suspected intra-articular hip pathology. British Journal of Radiology, 83(994): 861-867

12. Perdikakis E, Karachalios T, Katonis $P$ et al. (2011): Comparison of MR-arthrography and MDCT-arthrography for detection of labral and articular cartilage hip pathology. Skeletal Radiol., 40(11):1441-1447

13. Sahin M, Calisir C, Omeroglu $H$ et al. (2014): Evaluation of Labral Pathology and Hip Articular Cartilage in Patients with Femoroacetabular Impingement (FAI): Comparison of Multidetector CT Arthrography and MR Arthrography. Polish J Radiol., 79(10): 374-380. 